\title{
BAB-a New Ecommerce Mode in China
}

\author{
Xiuzhen Feng ${ }^{1}$ and Yibin $\mathrm{Hou}^{2}$ \\ School of Information, Renmin University of China \\ 59 Zhongguancun Ave, Beijing, 100872, P.R.China \\ dongming3699@126.com,jiangdeshan_01@163.com, \\ yuanfengren@sohu.com
}

\begin{abstract}
Information service business becomes the predominant industry in 21 st century, and eCommerce which has become the focus that all countries and large corporation compete for is being improved and perfected ceaselessly. Since China is very different from the west in social structure and culture characteristic, B2B develops slowly in China [1,2]. In order to extend ecommerce more smoothly and successfully in China, the important factor is the reorientation and reorganization of the middle link in the actual circumstance of China. BAB business mode made up the bottleneck problem that restraint China's ECommerce development in a certain extent and match the currently environment of China. The existence and participation of intermediary will reduce risk and improve the business efficiency of eCommerce market consumedly.
\end{abstract}

\section{Introduction}

In China, with the universality and development of computer and the network technology, eCommerce develops rapidly. Numerous information technique business enterprises, venture investment corporation etc, develop eCommerce in succession. The development prospect of eCommerce is doubtless extremely vast, but to expand eCommerce smoothly in the whole nation still has a lot of problem to resolve. The existence of intermediary can reduce market risk and improve market business efficiency, thus becomes a link between both sides in business [4,5]. BAB eCommerce mode can effectively get the function of intermediary together, which is a new approach to resolve the bottleneck problem especially trust and security in extending eCommerce in China. The business mode is being explored and improved 
positively at present, and Chinabab is an eCommerce website based on BAB mode $[14]$.

\section{Pushing forward eCommerce needs suitable conditions in China.}

As a new form of economy, eCommerce has its own features and needs to be support in special environment. China should create favorable conditions for the progress of eCommerce and take countermeasures to get rid of barriers and encourage its development [3].

\subsection{The development of ECommerce in china}

The eCommerce is a new subject developing very quickly. People generally understand eCommerce as a kind of business activity on the platform of internet. In China, eCommerce focuses on advancing B2B (Business to Business), and gives consideration on B2C (Business to Consumer) at the same time. B2B which comes into being at the earliest stage in the United States can lower the operation cost of supply chain between vendee and bargainor, reduce intermediary, cut down transaction costs, promote bargain accomplishing more easily, improve trade efficiency, so it develops quickly recently and become the mainstream of eCommerce.

Some eCommerce applications have already appeared in China, which are comparatively successful and starting gaining profit, such as alibaba. Since exterior environment of infrastructure is improved further, eCommerce gets it in gear all round and wins initial success in China.

\subsection{The bottleneck problem that restrict the development of ecommerce.}

The development prospect of eCommerce is doubtless extremely vast, but to expand eCommerce smoothly in the whole nation still has a lot of problem to resolve. Since China is very different from the west in social structure and culture characteristic, $\mathrm{B} 2 \mathrm{~B}$ develops slowly in China. There are a few main reasons as follows $[1,2,3]$ :

(1) The construction of credit standing environment is lag. China's credit system has not been built completely and is not perfect enough. Under the circumstances, enterprise which does not keep its word usually makes more profit than that which keeps its word.

(2) The channel of information is not open. Business enterprises can't provide market and source information in demand mutually, resulting in the unbalance of production \& sales.

(3) Enterprises have not formed market ideas fully. In china, marketplace intensive degree is not high, management is extensive, intermediate links are excessive, the efficiency of supply chain is poor and waste is more. 
(4)The relative service system is not perfect. The logistics channel is obstructed, logistics distribution system is faulty, and the delivery service of on-line shopping is not rapid. On-line paying system is not perfect. A lot of companies are still accustomed to traditional payment for the sake of safety.

(5) The legal system isn't sound and lacks new market rules for eCommerce. Traditional market rules for business affairs are still put into effect.

(6) The service provided by different agencies is faulty in market.

For the characteristics of network, while reducing the transaction cost, ECommerce also brings about some problems such as the difficulty to ascertain the credit of both sides in business. These problems lower the bargain efficiency in market. In order to complete trade smoothly, effective intermediate agent need to get involved, provide relevant information about product and business credit of both sides. The participation of intermediary will improve the bargain efficiency of eCommerce consumedly.

\subsection{Introduction to Electronic intermediary.}

There is no unified definition of intermediary by now. Generally, we think intermediary is a professional organization which accesses market as a self-governed third-party and embarks communication 、notarization、monitoring, consultation on market access 、 market competition 、 market transaction orders 、 market entanglement and others. It doesn't engage in the activity of commodity and service transaction directly [12]. Electronic intermediary is like a bridge connecting vendee and bargainor, which realizes all functions traditional intermediary has based on network. Of course, there are some new functions with Electronic intermediary.

The development of eCommerce has made some traditional intermediaries die out. At the same time, some new Intermediaries come forth [5,13]. These intermediaries are based on electronic technology and advanced management mode. They can offer more comprehensive service than traditional intermediaries do, although all of them increase the cost of value chain between vendee and bargainor [4].

\subsection{Electronic intermediary can play important roles in eCommerce.}

Electronic and traditional intermediaries share some common roles, such as cost reduction, aggregation, facilitation and market information provision. Electronic intermediaries have their own characteristics too. They are expounded as follows $[6,7,9,11,12]$ :

(1) Aggregation

Electronic intermediaries can provide the location for potential sellers to gather together, to share some public fundaments and customers, which forms scale economy and scope economy to lower the market access cost for sellers. Further more, Electronic intermediaries break the limitation of time and space to present many kinds of commodities to buyers.

(2)Providing market information 
The product price is a key factor for buyers to consider whether buy it or not. Electronic intermediaries can list the price of the same product made by different producers, where buyers can compare them by themselves. They also can narrate the quality of products.

(3)Serving as an electronic Marketplace

An electronic intermediary serves as B2B electronic marketplace where qualified members can post requests to buy or sell. An electronic intermediary provides the collection of many demands for buyers and many products for sellers effectively via the internet.

(4) Providing credit assurance

Members who want to bargain via an electronic intermediary must be qualified. An electronic intermediary must promise that buyers or sellers are legal to transact with each other.

(5) Online feedback

Buyers can communicate the quality information of product bought from producers via chat system、BBS etc. provided by an electronic intermediary. Other buyers can obtain more information from browsing the given topics.

(6)Online Auction

Via Internet, qualified members can participate in online Auction without the limitation of time and space. Online Auction can get more people together to provide their own price for products which they like and people need not go out for bidding block.

\section{The BAB mode is suitable to the development of Ecommerce in China.}

\subsection{It is required for the third party to get involved in overcoming the bottleneck problem.}

The B2B mode which spreads currently is to describe a business enterprise to carry on bargain on modern network, which makes no difference with work performed by hand in the business mode. The eCommerce can reduce intermediary and cut down transaction cost to some extent [8]. However in China, how to build a safe and reliable trade platform for enterprises has already become an urgent problem to resolve for ECommerce. The progress of any new productivity can cause the change of production relations by all means. For the actual circumstance of China, one of importance factor is the reorientation and reorganization of the middle link.

Because there are some deficiencies in understanding information such as product quality , price and mutual credit between both sides in the eCommerce market, in other words, information asymmetry, sometimes the completion of trade need the interposition of third party $[6,11]$. The more serious the indetermination of quality information is, the more intense the market demand for business intermediary is. It is not necessary that intermediary is an expert in product quality and price, or 
special organization in credit survey, but intermediary provides a place for numerous business enterprises and customers with shared information. The function similar to "bulletin board" is also able to play a certain role to guarantee trade credit of both sides.

It is generally believed that business intermediary is an essential element in market economy in micro-economics. Intermediary gains economy benefit depending on collecting, arranging and announcing concerned information, and becomes a link between both sides in business. Its existence can reduce market risk and improve market business efficiency.

\subsection{The introduction of BAB business mode.}

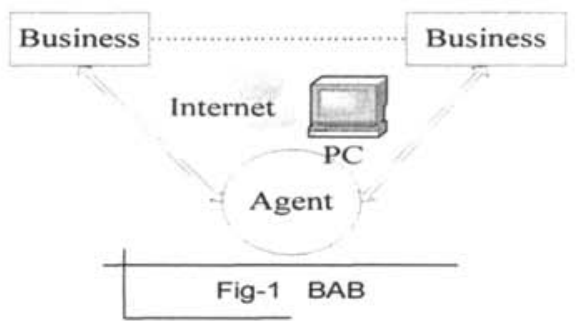

Fig.1. $B A B$

BAB stands for "Business-Agent-Business". BAB based on B2B is a kind of new modes for eCommerce among business enterprises. Its essence is to resolve the confidence problem among business enterprises. Its purpose is to create a reliable ecommerce environment including traffic 、 fund stream、logistics and knowledge stream, which makes up the deficiency of B2B ecommerce mode. Its trait is that the business enterprise carries on the commercial activity through a transaction platform which relies on the modern information technology, provides overall process and all-directions service and is a high degree of integration. This platform based on the network and the computer, supported with abundant information and knowledge, put into practice by the personnel with rich experience, is a kind of whole new business mode.

The main characteristics of $\mathrm{BAB}$ are as follows: utilization of up to date information technology; Omni-directional and entire process commercial support including information issue and information inquiry、identity authentication 、 negotiating contracts , payment logistics; Safe guarantee with man-machine union and multi- links.

\subsection{The realization and function of agent}

In the $\mathrm{BAB}$ ecommerce mode, " $\mathrm{A}$ " means the agent that represents business and service platform, which can also be referred to trade advisors or service advisors in the agency. The agents join the business as a third party to control the whole trade 
process and provide secure and reliable services for both buyers and sellers. This is a new approach to resolve the bottleneck problem about trust and security in extending eCommerce in China.

In ecommerce environment, the business agency framework includes technique support and service platform, digital authentication technique and organization, commercial bank, 3rd party logistics and 4th logistics-sustained technique and service, third party quality inspection service and enterprise credit evaluating organization and mechanism etc.

"A" is not BAB business platform itself, but is the aggregation which is assembled by $\mathrm{BAB}$ business platform and is made up with digital authentication system, bank, reliable logistics enterprise, quality inspection organization and enterprise's credit evaluating institution. The aggregate which bases on the responsibility taken in hand by each other and technical reliability, builds up credit system of $\mathrm{BAB}$ business platform, which provides the whole process and alldirections services of new ecommerce for user.

With the functions like trade processes control, risk control, business matching, resource allocation and individual recommended, members in the process can benefit from their partners, agents, etc.

\subsection{BAB platform provides necessary service and fundamental condition for business enterprises in eCommerce.}

$\mathrm{BAB}$ is different from other e-intermediaries. $\mathrm{BAB}$ mode bands technology means offered in network and guarantee provided by trusted Agent together. It integrates the whole process of identity authentication, information service, online payment, logistics distribution etc. It provides unified and reliable platform, and realize "three flows-in-one" (information flow, fund flow, material flow).All of these provide necessary service and fundamental condition for eCommerce between enterprises.

$\mathrm{BAB}$ platform supports many business activities, such as spot transactions, barter, future transaction, resource matching, online auction, etc. It also offers digital certification, digital signature and many other mechanisms which are prerequisite in a secure eCommerce platform. Meanwhile, its particular risk controls mechanism guarantees credit of enterprises. The whole business process is harmonized and supervised by "A", which offers overall services from searching business partners to accomplishing the whole trade process for business enterprises online. This is real ecommerce trade.

Specifically, from user's perspective, they can enjoy service from BAB platform as follows:

(1) Online trading and risk control in the whole process.

By means of forming strategy cooperation partnership with CA (Certificate Authority), bank, Logistics Company, third party credit rating agency etc, it provides all-round support and risk control mechanism for online business between qualified members.

(2)Providing automatic and manual matching and promoting cooperation service for various types of business activities, such as bargaining, replacement, future transaction, online auction, lease etc. 
(3) Resource matching service.

According to what the business enterprise needs, the platform can match 、 collocate and integrate resource such as material, information, knowledge and the capital resources on many sides. It provides various special services with distinct characteristics to exploit the potential value fully and makes them win together.

(4) Individual recommendation service.

Making use of Web mining technique and social network analysis technique, it can dig out latent demand of enterprise and possible business partners in future thereby can carry on business matching and individual recommendation more effectively.

\section{A Case Study-Chinabab}

www.chinabab.cn is an eCommerce website based on BAB business mode. This project is sponsored by Development Research Center of State Council P.R China. Universities such as Renmin University of China, Tianjin University, Tongji University etc. and Enterprises have participated in the project to explore a new business mode according with the development of eCommerce in China. The project team has already built a fundamental framework by investigation 、 discussion. evolvement with theory and practice, and developed the chinabab platform in about one year. We have participated in designing and developing parts of chinabab. We'll expatiate the contents of the website and draw a comparison between alibaba and chinabab.

\subsection{The contents of the website}

In this website, " $A$ " is an aggregation composed of Beijing Certificate Authority, China Merchants Bank, Guangdong Development Bank, Datian logistics, China Certification \& Inspection Group etc. Via the website, " $A$ " gathers information, financing, logistics, knowledge together to provide a trusty transaction environment. "A" provides service for the whole electronic transaction process, which are expanded next.

(A)Online Service. As a qualified member of chinabab, you can enjoy service below after logon. (1)Certificate Authority. To ensure chinabab platform safe and trusty, every member must be qualified. Members use their real names to transact with each other. Chinabab and Beijing Certificate Authority grant members a unique medium respectively, which is used to authenticate identity, sign contract. (2)Online Negotiation \& Signature.Chinabab provides online video service. Most of business, negotiations, making a contract all can be completed via chinabab. To a certain extent, the service reduces business cost and enhances transaction efficiency. (3)Online payment. Cooperating with China Merchants Bank, Guangdong Development Bank, chinabab provides online payment service. However, it owns a product E-Tong to make transaction more convenient inside the website. (4) Contract inventory. Chinabab offers various business contract templates to provide references, which make sellers and buyers, sign contracts more effectively. (5) Providing 
logistics schemes. Cooperating with China Certification \& Inspection Group, chinabab provides third-part Inspection service. The reports of inspection \& logistics are evidences for payment. (6)Providing suggestions of consultants. There are many professionals in chinabab. They can provide individuation service for buyers or sellers.

(B) Network Application service about online operation.Chinabab provides point-to-point, face-to-face service for enterprises respectively, for their deficiency in the faculty of network application. The contents of service are:(1) Training employees for necessary technology and business.(2) Founding websites for enterprises freely.(3) Helping enterprises set up OA,ERP,CRM systems

(C) Offline service.The maturity of service not only includes online service, but also involves offline service.(1)Providing reports about industry trends for members regularly.(2)Organizing clientele parties such as special topic lecture vase study conference, project argumentation conference.(3)Business consultation service via telephone.(4)Accepting member's consignations informed by telephone

(E) E-tong. E-tong is a payment tool in chinabab system. Qualified members can open their own E-tong accounts. The account of E-tong is monitored and managed by cooperation banks. E-tong is fit for enterprises which are lack of cash temporarily. Enterprises can obtain E-tong by impawning goods、 resource. Using E-tong makes enterprises activate their assets.

With multi-faceted service, chinabab wants to achieve objectives below:

(1) Establishing a public information exchange platform. As a qualified member, you can post you requests on the website. Other members can browse them to search for their appropriate business partners.

(2) Setting up resource operation mechanism. Enterprises and relatives compose a complexity network. Based on the website, Enterprises get dispersive organizations together to form an effective industry group, which brings into play Aggregation Effect adequately.

(3) Forming a trusty transaction environment of eCommerce. Under cooperation with banks, authority organizations etc., chinabab brings many enterprises into an honest trade circumstance to fulfill their business.

\subsection{A Comparison between Chinabab and Alibaba}

Alibaba is a famous brand of B2B eCommerce, which is the biggest online transaction market through the world currently. In this part, we will look for the differences between Alibaba and Chinabab. These differences are presented in Tab-1 below.

Tab 1. A Comparison between Chinabab and Alibaba

\begin{tabular}{|c|c|c|}
\hline Items & Chinabab & Alibaba \\
\hline & $\begin{array}{c}\text { Beijing Certificate Authority, } \\
\text { China Merchants Bank, } \\
\text { Guangdong Development Bank, } \\
\text { Datian logistics, } \\
\text { China Certification \& Inspection }\end{array}$ & $\begin{array}{c}\text { Yahoo, } \\
\text { Industrial and Commercial Bank } \\
\text { of China } \\
\text { etc }\end{array}$ \\
\hline
\end{tabular}




\begin{tabular}{|c|c|c|}
\hline & $\begin{array}{c}\text { Group } \\
\text { arbitration organizations }\end{array}$ \\
\hline Settlement System & E-tong & Alipay \\
\hline Logistics service & Datian logistics & No \\
\hline Member authentication & Beijing Certificate Authority, & $\begin{array}{c}\text { Shanghai Biz-credit Online } \\
\text { Service Co., Ltd }\end{array}$ \\
\hline Contract template & Yes & No \\
\hline Online signature & Yes & No \\
\hline Cargo Inspection & $\begin{array}{c}\text { China Certification \& Inspection } \\
\text { Group }\end{array}$ & No \\
\hline
\end{tabular}

From Tab-1 above, we can conclude that chinabab concentrates on the whole process of transaction, provides logistics service and risk control to reduce cost and benefit both buyers and sellers.

\section{Conclusion}

It can be seen from above that BAB business mode make up the bottleneck problem that restraint China's eCommerce development in a certain extent and match the current environment of China, especially in some cases such as the enterprise which transforms to the market economy, the credit system in the process of forming, enterprise leader's actual situation, the imperfection of advisory service system. China ought to try to investigate 、explore、carry out 、improve and perfect the implementation means of $\mathrm{BAB}$ business mode. $\mathrm{BAB}$ platform should be established by competent organization to improve business efficiency and benefit, which can extend eCommerce more smoothly and successfully in China.

\section{References}

1. H.X. Wang, S.Z. Lang and Y. Li, About Some Difficulties and Countermeasure during the Development of EC in China, Nanjing University of Science and Technology. Nanjing 210094.

2. Z.H. Liu and Z.L. Ge, Research on the Solutions and the questions of the Electronic Commerce Development in China. Year 2006 Graduate Paper, The Number of School:10269 ID: Zy0392010006.

3. Z. He , Features and Barriers to the Development of Electronic Business. Commercial Research , 156-157(2002).

4. R. Wigand and R. Benjamin, Electronic Markets and Virtual Value Chains on the information Superhighway, Sloan Management Review ,52-57(1995). 
5. Sarkar, Mitrabarun, Brian Butler and Charles Steinfield. Cybermediaries in Electronic Marketspace: Towards Theory Building, Journal of Business Research ,1998(41),215-221(1998).

6. Choi,Stahl and Whinston, Intermediation, Contracts and Micropayments in Electronic Commerce, Electronic Markets Newsletter, 1997(4).

7. J.Y. Wang and Y. Gao, The Model of Electronic Business Intermediary, Journal of LiaoDong University ,5,2005.

8. C. Stephen. Strategic Management of Electronic Commerce, Manchester Business School, John Wiley \& Sons, 2001.

9. Bailey and P. Joseph, Intermediation and Electronic Markets: Aggregation and Pricing in Internet Commerce, Cambridge: Thesis, Technology, Management and Policy, Massachusetts Institute of Technology, 1998

10. D.C. Croson and M.G. Jacobides, Agency Relationships and Monitoring in Electronic Commerce, International Journal of Electronic Commerce, (3),6582(1997).

11. Bailey, P. Joseph and J.Y. Bakos, An Exploratory Study of the Emerging Role of Electronic Intermediaries, International Journal of Electronic Commerce, 1(3),7-20, (1997).

12. X.Q. Ke, Economic Analysis of Intermediaries in the Electronic Commerce Market, Beijing: Tsinghua University,2004.

13. M.C. Alina, A thesis submitted to the faculty of the graduate school of the university of Minnesota, Intermediation in Electronic Commerce, 2001.

14. http://www.chinabab.cn. 